\title{
COEFFICIENT OF EFFICIENCY IN PEDAGOGICAL AND SCIENTIFIC WORK OF A TEACHER AND A GROUP OF UNIVERSITY TEACHERS
}

Financial resources are provided for realization of pedagogical performance (PP) and scientific performance (SP) at the university. Efficiency of its usage is subject of research for many researchers. In this paper we show practical quantification model of PP and SP of university teacher and university organizational units (i.e. groups of teachers, university department, groups of departments, faculty, groups of faculties, university). We respect recommended expenditure ratio $P P: S P=60: 40$ of provided financial resources.

Key words: Coefficient of Efficiency, Measurability of Pedagogical and Scientific Work, University Teacher.

\section{Introduction}

Coefficient of Efficiency $E=\frac{\text { Input }}{\text { Output }}$ of an aggregated basic university teacher's work performance per one academic year is studied using analytical methods and graphic instruments with regard to equilibrium $E=1$. If $E<1$ then the value of performance is lower than invested financial resources and it is necessary to seek the cause of such negative occurrence. If $E>1$ then the proven work performance of university teacher or organisational unit should be additionally appreciated, although norms should not be increased. Expected equilibrium $E=1$ might exhibit certain signs of instability if unit quality (balanced, standardized) $P P(S P)$ for performance evaluation is set incorrectly.

\section{Measurability of the basic pedagogical performance}

Quality of university teacher's $P P$ per one academic year is defined by the following formula:

$$
\begin{aligned}
& P P=\sum_{i}(N S G)_{i}(N S C)_{i}+\sum_{j}(N D T)_{j}(N S C)_{j}+ \\
& +\sum_{k}(N M T)_{k}(N S C)_{k}+\sum_{l}(N B T)_{l}(N S C)_{l}+ \\
& +\sum_{m}(N P G)_{m}(N S C)_{m}
\end{aligned}
$$

where $N S G$ is number of supervised study groups, $N D T$ is number of supervised dissertation theses, $N M T$ is number of supervised master theses, $N B T$ is number of supervised bachelor theses, $N P G$ is number of supervised scientific, professional and artistic activity groups and NSC is number of standard credits. Proposed number of standard credits is indicated in the Table 1 . In the brackets after the number of standard credits NSC next to each item is indicated number of optimal occurrences $\mathrm{NOO}$ of given item (in total maximum of points):

Suggested number of standardised credits (formula for $P P$ ) Tab. 1

\begin{tabular}{|l|c|c|c|c|c|}
\hline & $N S G$ & $N D T$ & $N M T$ & $N B T$ & $N P G$ \\
\hline$N S C(N O O)$ & $4(5)$ & $12(1)$ & $6(2)$ & $4(3)$ & $4(1)$ \\
\hline
\end{tabular}

\section{Measurability of basic scientific performance}

Quality of university teacher's $S P$ per one academic year is defined by the following formula:

$$
\begin{aligned}
& S P=\sum_{i}(N P M)_{i}(N S C)_{i}+\sum_{j}(N S A)_{j}(N S C)_{j}+ \\
& +\sum_{k}(N P A)_{k}(N S C)_{k}+\sum_{l}(N R P)_{l}(N S C)_{l}+ \\
& +\sum_{m}(N Q P)_{m}(N S C)_{m},
\end{aligned}
$$

where $N P M$ is the number of published scientific and professional monographs, $N S A$ is the number of published scientific articles, $N P A$ is the number of published professional articles, $N R P$ is the number of reviewed scientific and professional papers, $N Q P$ is the number of cited scientific and professional papers, NSC is the number of

\footnotetext{
* Dusan Mamrilla ${ }^{1}$, Gabriela Kravcakova ${ }^{2}$

${ }^{1}$ Faculty of Management PU in Presov, Presov, Slovakia, dusan.mamrilla@gmail.com

${ }^{2}$ Faculty of Public Administration, UPJS in Kosice, Kosice, Slovakia
} 
standard credits. Proposed number of standard credits is indicated in the Table 2. In the brackets after the number of standard credits $N S C$ next to the each item is indicated number of optimal occurrences $N O O$ of given item (in total maximum of 40 points if we do not include separately evaluated item NPM):

Proposed number of standardized credits (the formula for $S P$ )

\begin{tabular}{|c|c|c|c|c|c|}
\hline & $N P M$ & $N S A$ & $N P A$ & $N R P$ & $N Q P$ \\
\hline$N S C(N O O)$ & $20(1)$ & $15(1)$ & $10(1)$ & $5(2)$ & $5(1)$ \\
\hline
\end{tabular}

If university teacher receives at least 60 points for the basic pedagogical performance $P P$ and 40 points for basic scientific performance $S P$ then the set criteria were met and we can conclude that standardized basic work performance was achieved. Formulas for $P P$ and $S P$ may be modified if the ratio $P P: S P=60: 40$ is maintained.

Pedagogical university teacher's performance $P P$ can be specified in a greater detail, however quality level and optimal quantification of operations noted below are subjects to further research and its results are beyond capacity of this article. Here we present only a list of possible items [4].

\section{Direct pedagogical activities:}

Lecturing in full-time study programmes; facilitating seminars and workshops in full-time study programmes; lecturing (consulting) in doctoral studies; leading consultations in part-time study programmes; leading excursions and internship programs for students.

\section{Indirect pedagogical activities:}

preparation of lectures for full-time study programmes; preparation of seminars and workshops for full-time study programmes; consulting hours for students (personal and electronic); preparation of lectures (consultations) for doctoral studies; preparation of consultations for part-time study programmes; development of tests, exam papers and tasks for semester and final evaluation of students; evaluation of full-time and part-time students during the semester (evaluation of course papers, projects, etc.); final evaluation of fulltime and part-time students; examination of doctoral students at the end of course syllabus; membership in a state exam commission; membership in rigorous commission; membership in commission for examination of doctoral students; supervision of bachelor theses; supervision of master theses; supervision of rigorous theses; supervision of dissertation theses; revision of bachelor theses; revision of master theses; revision of rigorous theses; revision of dissertation theses; revision of habilitation and inauguration papers; management of SR\&DA (Student research and development activities) and other activities related to the pedagogical activities (record of results of passing a subject in academic information system, creation of themes for theses, preparation of written materials for students, etc.).

Scientific university teacher's performance $S P$ can be specified in a greater detail. E.g. we could take into account percentage share of an author in publications with more than one author as [2] and [3] are. However quality level and optimal quantification of operations noted below are subject to further research and its results are beyond capacity of this article. Here we present only a list of possible items.

\section{Scientific research and publication activities:}

Creation of a scientific monograph; chapters in scientific monographs; academic textbook creation; chapters in academic textbooks; scientific articles in journals; almanacs and monographs; presentations in the conferences; reports about solved scientific research tasks; copyright certificates, patents and inventions; published professional books; chapters in professional books; textbooks for primary and secondary schools; lecture scripts and notes; chapters in lecture scripts and notes; professional articles in journals and almanacs; abstracts, posters, slogans in technical terminology dictionaries, standards, norms, translations; audio-visual works, works of art; reviews, reports about research projects; leading the team of authors creating monographs, textbooks, lecture scripts and notes; implementation of research activities; management of grant and non-grant projects (departmental, faculty, etc.) - team management, administration; membership in a scientific school council; membership in a commission for study fields and joint commissions for study fields; membership in a committee for project review; membership in an editorial board of a journal; other activities connected with scientific research (project development, organizational work, conference management).

\section{Other activities:}

learning new knowledge; field of study supervisor; course coordinator; member of rector's advisory board; member of dean's advisory board; member of an accreditation committee (of ministry, school, work group); member of the Academic Senate; position in the Trade Union; Head of Department; Deputy Head of Department; Department Secretary; training activities in the faculty (university of $3^{\text {rd }}$ age, professional training courses and seminars); departmental meetings; ESF project coordinator; ESF project team member.

\section{The Coefficient of efficiency}

The item Output in the formula for the Coefficient of efficiency $E$ of an aggregated basic university teacher's work performance per one academic year can be determined by the formula:

$$
\text { Output }=\frac{P P+S P}{100} A T W,
$$


where $A T W$ is an annual tariff wage (gross) determined by statute or other linking regulation.

The item Input in the formula for the Coefficient of efficiency $E$ of an aggregated basic university teacher's work performance per one academic year can be determined by the formula:

$$
\text { Input }=A T W+B N F,
$$

where $B N F$ are financial benefits (gross) received above the framework $A T W$.

The Coefficient of efficiency $E$ of an aggregated basic university teacher's work performance per one academic year can be determined by the formula:

$$
E=\frac{\text { Output }}{\text { Input }}=\frac{P P+S P}{100} \frac{A T W}{A T W+B N F} .
$$

In general, the Coefficient of efficiency $E=\frac{P P+S P}{100}$. $\overline{A T W+B N F}$ is applied to a range of university teachers by a function of four independent real variables $P P, S P, A T W$ and $B N F$ where $P P \geq 0, S P \geq 0, A T W>0, B N F \geq 0, \mathrm{E} \in[0, \infty)$. Balanced state $E=1$ occurs, for example, when $(P P, S P, A T W, B N F)=(60$, 40, $A T W, 0)$

If we assume that $B N F=0$ then $E=\frac{P P+S P}{100}$ The performance of university teacher can be stated in percentage, it applies that $E(\%)=(P P+S P) \frac{A T W}{A T W+B N F}$, respectively $E(\%)=P P+S P$ if $B N F=0$.

\section{The specific model situation and its evaluation}

Suppose that the organisational unit of university consists of $n \geq 1, n \in N$ teachers. This may be one teacher, a group of several professors, several associated professors, several associates, several assistants in the department, but also a group of all teachers in the department, and so forth.

The Coefficient of efficiency $E$ of the aggregated basic university teacher's work performance $(n=1, i=1)$ and of a group of university teachers $(n>1, \mathrm{i}=1,2, \ldots, n)$ per one academic year, provided that the value of the group member's performance $P P+S P$ is comparable, can be determined by the formula:

$$
E=\frac{\text { Output }}{\text { Input }}=\frac{\sum_{i}\left((P P)_{i}(S P)_{i}\right)}{100 n} \frac{\sum_{i}(A T W)_{i}}{\sum_{i}\left((A T W)_{i}(B N F)_{i}\right)},
$$

where the expression $\frac{\sum_{i}\left((P P)_{i}(S P)_{i}\right)}{100 n}$ represents the mean value of random variable $X=\frac{(P P)_{1}+(S P)_{1}}{100}, \frac{(P P)_{2}+(S P)_{2}}{100}, \ldots$, $\frac{(P P)_{n}+(S P)_{n}}{100}$, the expression $\sum(A T W)_{i}$ represents the sum of tariff wages of all members of a group of university teachers per one academic year, the term $\sum\left((A T W)_{i}+(B N F)_{i}\right)$ represents the sum of the annual tariff wages and financial benefits of all members of a group of university teachers per one academic year.

The Coefficient of efficiency $E$ of the aggregated basic university teacher's work performance $(n=1, i=1)$ and of a group of university teachers $(n>1, \mathrm{i}=1,2, \ldots, n)$ per one academic year, provided that the value of the group member's performance $P P+$ $+S P$ is not comparable, can be determined by the formula:

$$
E=\frac{\text { Output }}{\text { Input }}=\frac{\sum_{i}\left(\frac{(P P)_{i}+(S P)_{i}}{100}(A T W)_{i}\right)}{\sum_{i}\left((A T W)_{i}+(B N F)_{i}\right)} .
$$

The Coefficient of efficiency $E$ of the aggregated basic university teacher's work performance $(n=1, i=1)$ and of a group of university teachers $(n>1, \mathrm{i}=1,2, \ldots, n)$ per one academic year, provided that the value $(A T W+B N F)$ of the group members is comparable and the random variable $Y=\left(E_{1}, E_{2}, \ldots, E_{n}\right)$ represents such Coefficients of efficiency of the aggregated basic university teacher's work performance within considered group that belong to normal statistical distribution can be determined by the formula:

$$
E=\frac{1}{n} \sum_{i} E_{i} \text { or } E=\operatorname{median}(Y)
$$

University may determine its own optimal level $E_{0} \leq 1$ for the Coefficient of efficiency of the aggregated basic university teacher's work performance or of a group of university teachers per one academic year.

Employee whose Coefficient of efficiency is $\breve{E}, \breve{E} \leq E_{0}$, can be loaded by one time cash compensation $x, x \geq 0$ (reduction of $\breve{E}$ to $E_{0}$ ):

$$
\begin{aligned}
& E_{0}=\frac{P P+S P}{100} \frac{A T W}{A T W+B N F-x}, \\
& x=B N F+\left(1-\frac{P P+S P}{100 E_{0}}\right) A T W .
\end{aligned}
$$

Employee, whose Coefficient of efficiency is $\widehat{E}, \widehat{E} \geq E_{0}$, can be rewarded by one time cash compensation $y, y \geq 0$ (reduction of $\widehat{E}$ to $E_{0}$ ):

$$
E_{0}=\frac{P P+S P}{100} \frac{A T W}{A T W+B N F-y},
$$


$y=-B N F+\left(\frac{P P+S P}{100 E_{0}}-1\right) A T W$.

\section{Example for calculating the Coefficient of efficiency and the amount of monetary compensation}

Consider the model situation according to Table 3 for two employees Empl1, Empl2.

Calculate the Coefficient of efficiency $E_{1}$ of the aggregated basic work performance of the employee Empl1 and the Coefficient of efficiency $E_{2}$ of the aggregated basic work performance of the employee Empl2.

Calculate the Coefficient of efficiency $E_{3}$ of the aggregated basic work performance of the group of employees Empl1 and Empl2 by applying the formula for comparable values $P P+S P$.

Calculate the Coefficient of efficiency $E_{4}$ of the aggregated basic work performance of the group of employees Empl1 and Empl2 by applying the formula for incomparable values $P P+S P$.

Calculate the Coefficient of efficiency $E_{5}$ of the aggregated basic work performance of the group of employees Empl1 and Empl2 by applying the formula for comparable values $A T W+B N F$.

Performance and income of workers

Tab. 3

\begin{tabular}{|l|c|c|c|c|c|c|}
\hline & $P P$ & $S P$ & $A T W$ & $B N F$ & $P P+S P$ & $A T W+B N F$ \\
\hline Empl1 & 59 & 30 & 1000 & 200 & 89 & 1200 \\
\hline Empl2 & 56 & 48 & 1200 & 300 & 104 & 1500 \\
\hline
\end{tabular}

Values $A T W$ and $B N F$ are presented in theoretical monetary terms. Then we have

$$
\begin{aligned}
E_{1} & =\frac{P P+S P}{100} \frac{A T W}{A T W+B N F}= \\
= & \frac{89}{100} \frac{1000}{1200} \approx 0.741666666 \\
E_{2}= & \frac{P P+S P}{100} \frac{A T W}{A T W+B N F}= \\
= & \frac{104}{100} \frac{1200}{1500}=0.832 \\
E_{3}= & \frac{\sum_{i}\left((P P)_{i}+(S P)_{i}\right)}{100 n} \frac{\sum_{i}(A T W)_{i}}{\sum_{i}\left((A T W)_{i}+\left(B N F_{i}\right)\right)}= \\
= & \frac{89+104}{200} \frac{1000+1200}{1200+1500} \approx 0.786296296
\end{aligned}
$$

$$
\begin{aligned}
E_{4}= & \frac{\sum_{i} \frac{(P P)_{i}+(S P)_{i}}{100}(A T W)_{i}}{\sum_{i}\left((A T W)_{i}+\left(B N F_{i}\right)\right)}= \\
= & \frac{\frac{89}{100} 1000+\frac{104}{100} 1200}{1200+1500} \approx 0.791851851 \\
E_{5}= & \frac{E_{1}+E_{2}}{2}=\text { median }\left(E_{1}, E_{2}\right)= \\
= & \frac{0.741666666+0.832}{2} \approx 0.786833333
\end{aligned}
$$

We can conclude from the calculations that the return of the invested financial resources in case the employee Empl1(Empl2) is at the level of $74.17 \%(83.20 \%)$.

The Coefficient of efficiency $E_{3}(\%)$ of the aggregated basic work performance of the group of employees Empl1 and Empl2, provided that the values $P P+S P$ of the group members are comparable, is on the level $78.63 \%$.

The Coefficient of efficiency $E_{4}(\%)$ of the aggregated basic work performance of the group of employees Empl1 and Empl2, provided that the values $P P+S P$ of the group members are incomparable, is on the level $79.19 \%$

The Coefficient of efficiency $E_{5}(\%)$ of the aggregated basic work performance of the group of employees Empl1 and Empl2, provided that the values $A T W+B N F$ of the group members are comparable, is on the level $78.68 \%$.

For given model situation applies that $E_{3}(\%) \approx E_{4}(\%) \approx$ $\approx E_{5}(\%) \approx 79 \%$.

Consider that the optimum level of the Coefficient of efficiency of the aggregated basic university teacher's work performance per one academic year is the value $E_{0}=0.832$. Then the employee Empl2 deserves zero cash compensation $x_{2}=0$ and the employee deserves payroll deduction in a form of single monetary compensation $x_{1}, x_{1} \geq 0$ :

$$
\begin{aligned}
x_{1} & =B N F+\left(1-\frac{P P+S P}{100 E_{0}}\right) A T W= \\
& =200+\left(1-\frac{89}{83.2}\right) 1000 \approx 130.2884615
\end{aligned}
$$

of theoretical monetary units.

Consider that the optimum level of the Coefficient of efficiency of the aggregated basic university teacher's work performance per one academic year is the value $E_{0}=0.741666666$. Then the employee Empl1 deserves zero cash compensation $y_{1}=0$ and the employee Empl2 deserves payroll bonus in a form of single monetary compensation $y_{2}, y_{2} \geq 0$ : 


$$
\begin{aligned}
y_{2} & =-B N F+\left(\frac{P P+S P}{100 E_{0}}-1\right) A T W= \\
& =-300+\left(\frac{104}{74.1666666}-1\right) 1200 \approx 182.6966307
\end{aligned}
$$

of theoretical monetary units.

\section{References}

[1] BORZIKOVA, J., MAMRILlA, D., VAGASKA, A.: Probability - Statistics (in Slovak), Elibrol Vranov n. Toplou, 2011. ISBN 97880-89528-16-5.

[2] DOROCIAKOVA, B., POBOCIKOVA, I.: Collection of Examples from Probability and Mathematical Statistics (in Slovak), EDIS University of Zilina 2005. ISBN 80-8070-384-1.

[3] GULDAN, V., MARCOKOVA, M.: Orthogonal Polynomials and Related Special Functions Applied in Geosciences and Engineering Computations, Communications - Scientific Letters of the University of Zilina, Vol. 12, No.1 (2010), pp. 12-15.

[4] KRAVCAKOVA, G.: System of Complex Assessment of Employees Efficiency (in Slovak), In: Efficiency of organisational unit accesses to its measurement and assessment, University of Matej Bel in Banska Bystrica 2005, pp. 172-177. ISBN 80-9680-805-2.

[5] KRAVCAKOVA, G.: Description of Instrument for Analysis of University Teacher's Work (in Slovak), In: Value of mental work for organisational unit and society, University of Pavol Jozef Safarik in Kosice 2010, pp. 201-211. ISBN 978-80-7097-847-4.

[6] LIPKOVA, L., MAMRILlA, D.: How to Classify Knowledge Level of Pupils (in Slovak), In: Technology of education 6, I/1993, Unia Didacta Slovaca, pp. 7-9.

[7] MACHAlOVA, A., MAMRILLA, D.: Collection of Problems from Mathematics for Management Specializations (in Slovak), Universum Presov 2000. ISBN 80-9677-537-5.

[8] McCLAVE, J. T., BENSON, P. G.: Statistics for Business and Economics, Dellen Publishing Company 1988.

[9] RAO, C. R.: Linear Methods of Statistical Induction and their Applications (in Slovak), Academia Praha, 1978. 